\title{
Pulmonary function assessment in children and teenagers before and after surgical treatment for rheumatic valve disease
}

\author{
Michele B. Caséca, ${ }^{1}$ Lívia B. de Andrade, ${ }^{2}$ Murilo C. A. de Britto ${ }^{3}$
}

\begin{abstract}
Objective: To assess pulmonary function in children and adolescents subjected to correction of rheumatic valve disease in order to quantify changes caused by factors inherent to surgery and rheumatic heart disease.

Methods: This was a longitudinal and quantitative intervention study, undertaken at a children's hospital that is a center of excellence for the state of Pernambuco (Instituto Materno Infantil de Pernambuco), between December 2004 and May 2005. Eighteen children suffering from rheumatic fever and indicated for surgery to repair or replace the mitral valve were assessed preoperatively and again on the first and fifth postoperative days. The parameters recorded were minute volume, rapid shallow breathing index, peak expiratory flow, forced vital capacity and inspiratory capacity.

Results: All patients were aged 8 to 17 years (mean $12.4 \pm 2.1$ ), they had a mean body mass index of $16.1 \pm 2.2$, and were weaned off invasive mechanical ventilation during the first 10 postoperative hours. All parameters had undergone significant deterioration on the first day (statistically significant, $p \leq 0.01$ ), demonstrating gradual improvement up to the last day of assessment, although, with the exception of minute volume which was no longer significantly different from the fourth day onwards $(p>0.01)$, without returning to baseline levels.

Conclusion: We observed that the pulmonary dysfunction that results from this type of heart surgery is maintained until at least the fifth postoperative day. It appears that this dysfunction is influenced by the pain and mechanical alterations caused by sternotomy and reduced pulmonary compliance post surgery.
\end{abstract}

J Pediatr (Rio J). 2006;82(2):144-50: Rheumatic fever, children, heart surgery, pulmonary function.

\section{Introduction}

Rheumatic fever is a multisystemic inflammatory disease that afflicts the child and juvenile population, ${ }^{1}$ and, despite a reduction in its incidence, it is still very common in developing countries. ${ }^{2,3}$

1. Fisioterapeuta, Real Hospital Português, Recife, PE, Brasil. Especializanda em UTI, Faculdade Redentor, Rio de Janeiro, RJ, Brasil. Mestranda, Universidade Lusófona de Lisboa, Portugal.

2. Mestre, Universidade Federal de Pernambuco (UFPE), Recife, PE, Brasil. Especialista em Fisioterapia Cardiorrespiratória, UFPE, Recife, PE, Brasil. Docente, Faculdade Integrada do Recife (FIR), Recife, PE, Brasil. Fisioterapeuta, Instituto Materno-Infantil de Pernambuco (IMIP), Recife, PE, Brasil.

3. Doutor, IMIP, Recife, PE, Brasil. Médico Pneumologista, IMIP, Recife, PE, Brasil. Coordenador, Mestrado em Saúde Materno-Infantil, IMIP, Recife, PE, Brasil.

Manuscript received Aug 16 2005, accepted for publication Jan 042006.

Suggested citation: Caséca MB, de Andrade LB, de Britto MC. Pulmonary function assessment in children and teenagers before and after surgical treatment for rheumatic valve disease. J Pediatr (Rio J). 2006;82:144-50.
Some of the most frequently affected systems are the cardiovascular, the musculoskeletal and the nervous systems. ${ }^{2,4}$ Cardiovascular involvement, in the form of endocarditis or valve failure, is currently the condition most linked with increased morbidity and mortality in this population ${ }^{2,3}$ and is the most severe complication of rheumatic fever, with consequent onset of chronic heart valve disease. ${ }^{5}$

Although there has recently been a reduction in the severity and frequency of rheumatic heart disease in children due to technical advances, ${ }^{6}$ significant numbers of young patients continue to suffer valve damage secondary to rheumatic fever, 4,7 with the mitral valve being the most often affected by this heart disease. $2,4,8$

A compromised respiratory system is also a very common characteristic of systemic rheumatic diseases, causing pulmonary abnormalities in approximately $74 \%$ 
of the patients affected. ${ }^{8}$ The most common pathological findings are interstitial fibrosis, followed by restrictive or obstructive pulmonary disorders. ${ }^{8,9}$ Fortunately, there are reports showing that, despite the frequency of pulmonary function (PF) involvement and its early onset in children with rheumatic fever, the pulmonary abnormalities observed are normally stable, with little or no progression ${ }^{10}$ and are not normally manifested in severe presentations. ${ }^{9}$

Furthermore, systemic rheumatic disease alters the structure of the lungs, thus compromising their function. Several different studies have reported that heart surgery is also an additional factor compromising lung function. Respiratory system function is undoubtedly affected during and after surgery, ${ }^{11}$ due to the pain caused by incisions and the myriad physiological changes caused by the operation. ${ }^{12}$

It is for these reasons that PF may be measured when children are assessed prior to major surgery, in order to quantify the severity of a disease that has already been diagnosed (pulmonary or cardiac), in addition to assessing the risks of surgery, such as, for example, sternotomy. ${ }^{13,14}$ This quantitative analysis, if performed early, can allow clinical interventions before irreversible lung damage sets in, thus making it possible to reduce early morbidity and mortality, ${ }^{15}$ since, when rapid changes in PF take place in these patients, they are intimately related with reduced survival. 16,17

Evidence does exist, albeit little publicized or disseminated, that PF is severely compromised after surgical correction of rheumatic valve disease in children, and that this is directly related to the type of surgical incision, to the degree of cardiopulmonary impairment resulting from surgery and to the rheumatic heart disease itself.

The objective of this study was therefore to evaluate the PF of children and adolescents before and after surgical correction of rheumatic valve disease, in order to quantify changes caused by factors inherent to surgery and rheumatic heart disease to the following respiratory parameters: minute volume, peak expiratory flow, inspiratory capacity and forced vital capacity.

\section{Materials and methods \\ Sample}

This study was carried out in the Cardiology Ward at the Instituto Materno-Infantil de Pernambuco (IMIP) between December 2004 and May 2005. Children and adolescents of both sexes aged 8 to 17 years and suffering from mitral valve failure as a result of rheumatic heart disease were enrolled if they underwent surgical correction for valve disease during the study period.
Patients were excluded if they: (I) exhibited cognitive or neurological deficit (demonstrated by an inability to understand the instructions for the PF tests); (II) developed hemodynamic instability (identified by fever, significant changes in arterial pressure or heart rate and severe hypoxemia); (III) were put on continuous oxygen therapy; (IV) had presented with a previous history of lung disease (such as asthma, bronchitis or pneumonia); (V) were under the effect of a sedative or in a reduced level of consciousness; (VI) exhibited severe pulmonary hypertension due to rheumatic heart disease (defined as pulmonary wedge pressure $>45 \mathrm{mmHg}$ ); or (VII) they could not be assessed because consent was not forthcoming.

\section{Study design}

This was a quantitative study with a longitudinal design assessing pulmonary function the day before surgery, and from the first to fifth postoperative days (POD).

The surgical procedures employed were mitral valve repair or replacement, as developed by Carpentier. ${ }^{18}$ The two procedures are very similar in terms of their dimensions and their risks and therefore the postoperative care required and possible complications are the same. Mediastinal drainage was used postoperatively with all children and lasted around 24 hours.

All patients were put on extracorporeal circulation and, for this reason, were given anticoagulants during the operation (heparin $4 \mathrm{mg} / \mathrm{kg}$ ). During the postoperative period, however, only those patients who had been fitted with mechanical valves required continued anticoagulation with warfarin $(5 \mathrm{mg} / \mathrm{kg})$.

In accordance with the protocol in force at our service, oral midazolam ( $0.5 \mathrm{mg} / \mathrm{kg}$ dose) was used for preanesthesia, induction was with fentanyl $(10-20 \mu \mathrm{g} / \mathrm{kg}$ dose), propofol (2-3 $\mathrm{mg} / \mathrm{kg}$ dose) and atracurium $(0.5 \mathrm{mg} / \mathrm{kg})$ and anesthesia was maintained thereafter with isoflurane.

Analgesia was maintained unchanged throughout the postoperative period, up until discharge from the intensive care unit, with all patients being given morphine $(0.1 \mathrm{mg} / \mathrm{kg})$ every 4 hours. The majority of patients were discharged from the ICU after 48 hours.

All patients were assessed bedside (45th Fowler position) and three measurements were taken for each parameter with the highest value being recorded. The preoperative assessment was an exception to this rule, since patients were given four attempts at each test to allow them the chance to learn how to perform each one in response to the examiner's verbal instructions.

The parameters analyzed were: (1) peak expiratory flow (PEF); (2) minute volume (VE); (3) forced vital capacity (FVC); (4) inspiratory capacity (IC). Peak 
expiratory flow was measured with a Boehringer Ingelheim ${ }^{\circledR}$ pediatric peak flow meter and VE, FVC and IC were measured with an Ohmeda Respirometer ${ }^{\circledR} 5420$ digital volume monitor set to pediatric mode. All parameters were evaluated by the same examiner throughout the study.

Data such as weight, height, body mass index (BMI), time on extracorporeal circulation (ECC), pulmonary capillary wedge pressure, respiratory auscultation findings, time intubated and postoperative complications, were recorded for all patients (transcribed directly from their medical records) on a data collection form.

None of the patients received any type of physiotherapy during their hospital stay.

\section{Protocol for pulmonary function assessment}

Peak expiratory flow was measured by requesting the patient to breath in as far as possible and then perform a forced expiration into the peak flow circuit mouthpiece.

VE was measured using a silicon pediatric facemask coupled to the digital volume monitor (Ohmeda Respirometer $^{\circledR}$ 5420). The mask was adapted to the patient's face, who was requested to breath naturally. VE was then calculated after the parameters tidal volume (VT) and respiratory rate (RR) had been obtained, VT converted to liters and the two factors multiplied. The equipment automatically records VT (in $\mathrm{ml}$ ) and RR for every expiration. The digital volume monitor is extremely sensitivity and so before recording data the examiner allowed the machine 15 seconds to adapt itself to each patient's respiration. After this pause, every VT value was observed for the next 15 seconds and the largest volume was recorded together with its corresponding RR figure.

Rapid shallow breathing index (RSBI) was calculated from the $V T$ and $R R$ values recorded in the previous evaluation, dividing RR by VT in liters.

Forced vital capacity was also measured using the digital volume monitor by requesting the patient to breath in to the maximum and then perform a forced maximum expiration in the facial mask. The monitor automatically records the maximum FVC (in $\mathrm{ml}$ ) at the end of the maneuver.

The monitor's reverse flow facility was then used to measure inspiratory capacity. In this mode the sensor is changed over and the monitor tests inspiratory flow. Once the monitor had been adjusted the patient was requested to breath in to the maximum having completed an expiration at rest (residual functional capacity) into the circuit via the facemask. The monitor automatically records IC (in $\mathrm{ml}$ ) at the end of the maneuver.

Each postoperative assessment took approximately 20 minutes and the preoperative assessments took ten minutes longer because the patients had to learn how to perform the tests. There was no fixed time of day for assessments, but the mealtimes and the subsequent hour were excluded to avoid episodes of gastroesophageal reflux and increased discomfort.

All participants were assessed prior to surgery and on postoperative days $1,2,3,4$ and 5 .

\section{Statistical analysis}

Data analysis employed descriptive statistical techniques to investigate the study sample, by means of calculating the frequency distributions of some of the variables collected and representing them graphically and by calculating descriptive measurements such as mean, minimum, maximum and standard deviation. The Wilcoxon test was used for comparative analysis of variables measured on 1st through POD 5 with their preoperative levels. All conclusions were based on a significance level of $1 \%(p \leq 0.01)$.

Excel 2000 and SPSS version 8.0 were used for these procedures.

\section{Ethical and legal considerations}

The study was approved by the Committee for Ethics and Research on Humans at our institution (IMIP) and formal consent was requested and obtained in advance from the parents or guardians of each child, in the form of a signed Free and Informed Consent Form.

\section{Results}

The sample comprised 18 individuals, $55.6 \%(n=10)$ of whom were female and $44.4 \%(n=8)$ male. Eleven of them underwent mitral valve replacement and seven valve repair. Their mean age was $12.4 \pm 2.1$ years, ranging from 8 to 17 years, their mean weight was $34.7 \pm 7.9 \mathrm{~kg}$ and mean height was $146 \pm 11 \mathrm{~cm}$. Mean BMI was $16.1 \pm 2.2 \mathrm{~kg} / \mathrm{cm}^{2}$ and the entire sample was in the underweight range $\left(B M I<18.5 \mathrm{~kg} / \mathrm{cm}^{2}\right.$ ) with the single exception of a child whose BMI was $19.84 \mathrm{~kg} / \mathrm{cm}^{2}$. Mean time on ECC was $63 \pm 17$ minutes and mean time intubated was $7.0 \pm 1.6$ hours. All patients were weaned off invasive mechanical ventilation within 10 hours of surgery.

Figures 1 through 4 present the comparative analysis for VE, PEF, FVC and IC, for the 1st to POD 5 with respect of their preoperative baseline values.

We can observe in Figure 1 that, in average terms, there was a significant postoperative reduction in VE on the POD 1, which then exhibited an accentuated rate of increase up to the POD 4 from which point on it reached levels statistically indistinguishable from the baseline value. We can also observe that, in average terms, after 
surgery PEF was significantly reduced on the POD 1 and exhibited a gradual increase up to the POD 5 by which point it had not yet reached levels statistically equal to the baseline figure (Figure 2). The same behavior can be observed for FVC and IC (Figures 3 and 4).

Table 1 lists the mean percentage reductions from baseline values for PEF, FVC and IC on PODs 1 through 5.

\section{Discussion}

Several different studies demonstrated the potential of cardiac surgery to compromise PF,19-23 although such studies are scarce for the pediatric population. 24-26 To the extent of our knowledge, this is the only study to

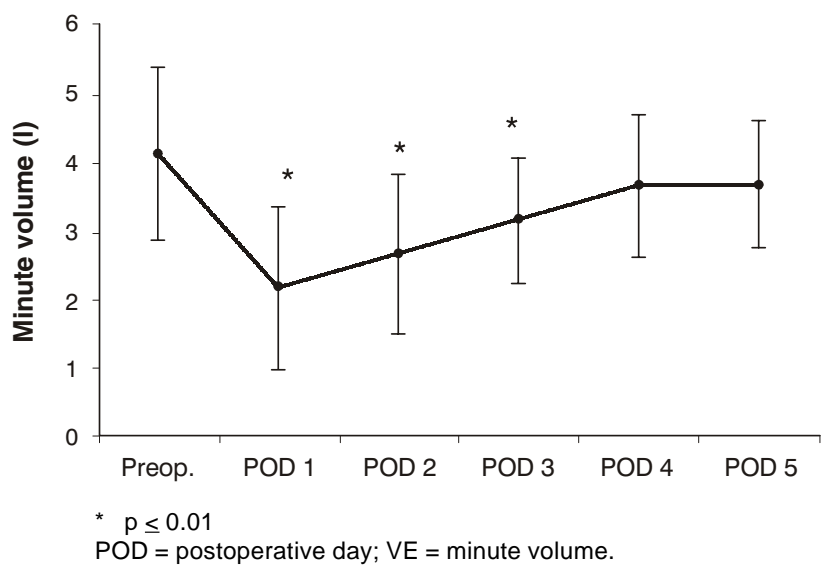

Figure 1 - Behavior of VE from preoperative day 1 to postoperative day 5

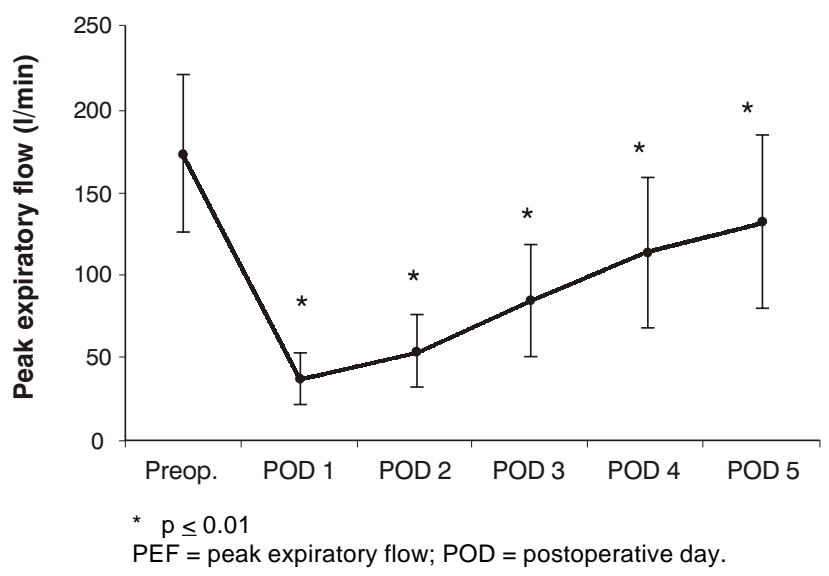

Figure 2 - Behavior of PEF from preoperative day 1 to postoperative day 5 have monitored the daily progress of PF over the first few postoperative days and compared it to preoperative baseline values. Some previous studies of both adults and children have assessed PF before, ${ }^{21}$ during or immediately after, ${ }^{24}$ or some days or months after such surgery. 22,26

The results of this study have demonstrated that all PF parameters remained significantly deteriorated until at least 5 days after surgery, with the exception of VE, which had returned to levels comparable with baseline levels from POD 4 onwards. Some other studies have also demonstrated varying degrees of pulmonary dysfunction over the short term after heart surgery, although the age groups involved were different. 23,24

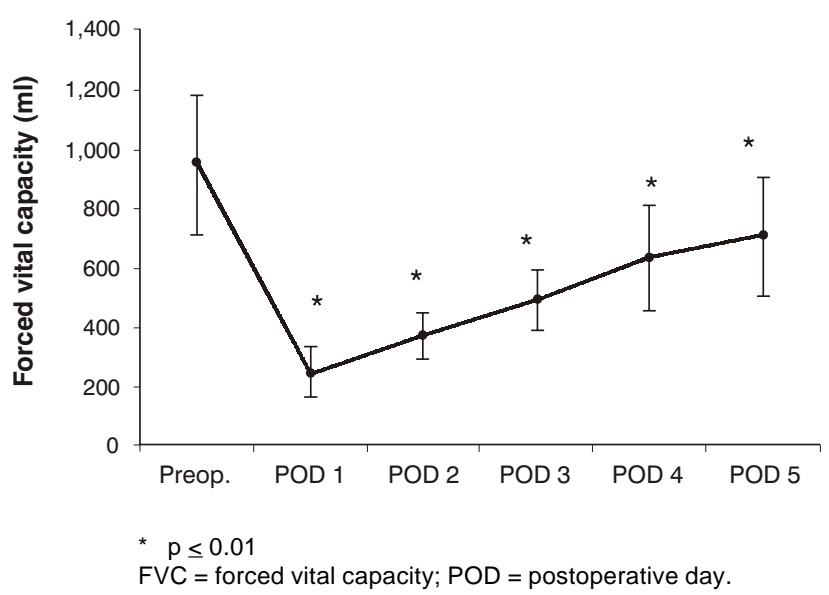

Figure 3 - Behavior of FVC from preoperative day 1 to postoperative day 5

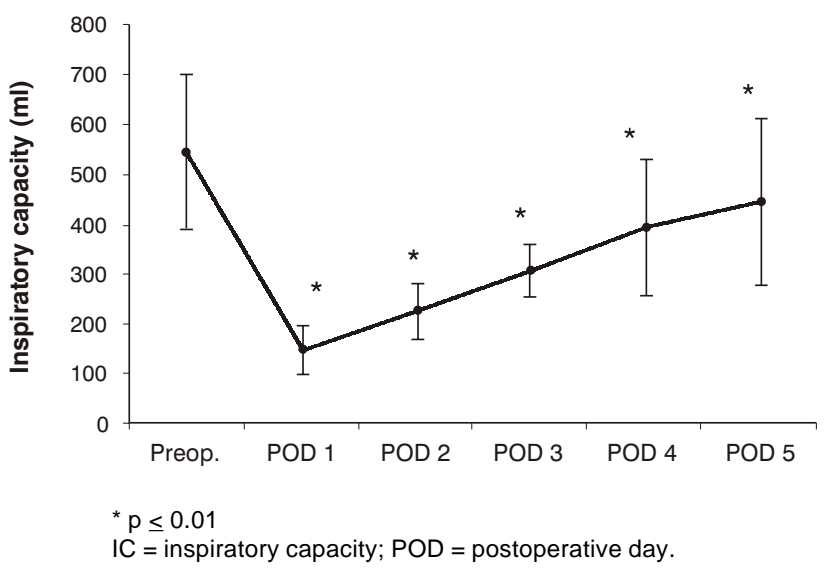

Figure 4 - Behavior of IC from preoperative day 1 to postoperative day 5 
Table 1 - Mean percentage postoperative reductions from baseline preoperative values for PEF, FVC and IC in 8 to 17 year-old mitral valve surgery patients (IMIP, 2004-2005)

\begin{tabular}{|c|c|c|c|c|c|c|c|c|c|}
\hline & \multicolumn{3}{|c|}{ PEF } & \multicolumn{3}{|c|}{ FVC } & \multicolumn{3}{|c|}{ IC } \\
\hline & $\begin{array}{c}\text { Mean } \\
(1 / \mathrm{min})\end{array}$ & SD & $\mathbf{p}$ & $\begin{array}{c}\text { Mean } \\
(\mathrm{ml})\end{array}$ & SD & $\mathbf{p}$ & $\begin{array}{c}\text { Mean } \\
(\mathrm{ml})\end{array}$ & SD & $\mathbf{p}$ \\
\hline POD 1 & 121 & 7.67 & $<0.001 *$ & 703.22 & 86.61 & $<0.001 *$ & 400.84 & 49.79 & $<0.001 *$ \\
\hline POD 2 & 113 & 14.91 & $<0.001 *$ & 583.44 & 78.94 & $<0.001 *$ & 321.67 & 56.29 & $<0.001 *$ \\
\hline POD 3 & 87 & 30.10 & $<0.001 *$ & 461.22 & 102.81 & $<0.001 *$ & 240.95 & 51.88 & $<0.001 *$ \\
\hline POD 4 & 58 & 41.89 & $<0.001 *$ & 317.5 & 180.83 & $<0.001 *$ & 152.51 & 135.62 & $<0.001 *$ \\
\hline POD 5 & 40 & 48.53 & $<0.001 *$ & 243.27 & 201.80 & $<0.001 *$ & 101.34 & 168.87 & $<0.001 *$ \\
\hline
\end{tabular}

FVC = forced vital capacity; IC = inspiratory capacity IMIP = Instituto Materno-Infantil de Pernambuco; PEF = peak expiratory flow; POD = postoperative day; $\mathrm{SD}=$ standard deviation.

* $\mathrm{p}$ value, Wilcoxon test.

On the first day after surgery a sudden and significant drop in mean VE was observed and this was maintained until postoperative day three. However, RR was observed to have quickened considerably compared with baseline. Since VE is the mathematical product of RR and VT, it was therefore concluded that this deterioration in VE was the result of a significant drop in VT. This data also allows us to calculate the RSBI, which is the quotient of RR by VT (in liters), which were greatly increased immediately after surgery and proceeded to fall as the days passed. Although there are no reports of the behavior of VE and RSBI after chest surgeries, these results demonstrate that there were significant alterations to both parameters.

The behavior of PEF, FVC and IC was similar, all were significantly reduced on POD 1 . Some studies have demonstrated variable behavior on these parameters after heart surgery. Shenkman et al. ${ }^{22}$ assessed the effects of elective heart surgery (including valve replacement) on PF over the short (3 weeks) and long term ( 3.5 months) in 50 adult patients. In agreement with our results, these authors concluded that FVC and PEF, among other parameters that were analyzed, were significantly reduced after surgery, and, although the exhibited discrete increases over time, were still affected an average of 3.5 months after surgery. Similarly, a further two studies also assessed FVC after heart surgery, concluding that FVC was significantly reduced until POD $7^{23}$ and $8,^{20}$ when compared with preoperative levels.

The only two studies we found of children that described the behavior of PF after heart surgery reported highly contradictory results. McGowan et al. ${ }^{24}$ assessed PF during the immediate postoperative period of bypass surgery on
12 children. Their findings demonstrate a significant reduction on FVC and $\mathrm{IC}$, in agreement with our results. In contrast, Sulc et al. ${ }^{26}$ observed that FVC and PEF did not exhibit significant differences from preoperative levels after evaluating 24 children before and after surgical correction of congenital heart disease. Nevertheless, the only postoperative assessment they made was after a mean period of 1.7 years, in addition to the sample being made up of children with simple heart disease (atrial septal defect), which was not the case in our study.

Much research has attempted to explain the causes of pulmonary dysfunction subsequent to chest surgery, but the factors responsible still need clarification. Sternotomy is one factor that could possibly be related to postoperative PF deterioration. Some authors attribute the effect to the pain caused by these procedures. Candaele et al. 27 assessed pain levels and PF (FVC and $V_{E F}$ ) in 31 adult aortic valve replacement patients. The authors divided their sample into two groups and compared pain and PF with conventional sternotomy with those resulting from an alternative sternotomy, concluding that FVC was reduced in 61 and 55\%, respectively, and that these reductions were still present in $17 \%$ one month after surgery, in both groups. Others have, however, attributed the weakened PF to changes in breathing patterns caused by sternotomy. Ragnarsdóttir et al. ${ }^{23}$ reported that the most important finding in their study was the observation that the respiratory patterns of their 20 patients had changed from predominantly abdominal (before surgery via sternotomy) to predominantly thoracic (after surgery), which was intimately related to the drop in PF. They also report that this was a reflection of the reduced abdominal and thoracic wall movement after sternotomy. 
One further possible factor that could be associated with compromised PF is the reduction in pulmonary compliance that takes place after cardiac surgery. Durand et al., ${ }^{21}$ observed a drop of approximately $30 \%$ in VC on POD 1, compared with preoperative levels. They also observed that CV increased gradually over the first week and that the reduction in CV was linked with increased respiratory work due to reduced pulmonary compliance, which would then improve as pulmonary mechanics gradually recover.

Factors like time on ECC and intubation are variables that could also be related to the pulmonary dysfunction we found. In the present study time on ECC did not exhibit any relationship with postoperative pulmonary dysfunction. Braun et al., ${ }^{19}$ studied adult bypass surgery patients and also failed to find a link between pulmonary dysfunction and time on ECC.

Only the study by Macguire et al. 28 confirmed whether the length of time children were intubated had an influence on PF. Furthermore, they concluded that whether children were extubated in the theatre, soon after arriving at the ICU or later on in ICU did not have an influence on the PF of their study population. We observe that the small variations in ECC and intubation times in our sample were not large enough to affect results.

We therefore conclude that pulmonary dysfunction occurs after open heart surgery in children suffering from rheumatic heart disease. Pulmonary function is significantly reduced on POD 1 and continues weakened up to POD 5 and does not regain preoperative levels after this length of time. This dysfunction does not appear to be influenced by factors such as the length of time in theatre and on invasive mechanical ventilation (time on ECC and time intubated), but appears to be caused by the pain and mechanical alterations suffered as a result of the surgical incision (sternotomy) and by reduced postoperative pulmonary compliance.

This study has certain limitations, such as a limited sample size and the impossibility of monitoring the children for longer because many of them had been referred from other cities and returned after hospital discharge.

Another limiting factor is the absence of a control group made up of individuals from the same age group and with the same severity of mitral damage, but without undergoing valve repair. Nevertheless, even without such a group, we can attribute the changes observed to the surgical intervention.

We therefore suggest that this study be extended with a larger sample and with the addition of physiotherapy during the postoperative period in order to investigate the impact of these interventions on pulmonary dysfunction in these children.

\section{Acknowledgements}

We are grateful to Dr. Cleuza Lapa for her receptivity and for that of her entire team of health professionals at the Cardiac Ward of the Instituto Materno-Infantil de Pernambuco (IMIP). We would also like to thank for Pulmocardio Fisioterapia for lending us their volume monitor, the respiratory physiotherapists $\mathrm{Dr}$. Doralice Ribeiro and Dr. Francimar Ferrari for their countless suggestions.

\section{References}

1. Moreira C, Carvalho MAP. Reumatologia: diagnóstico e tratamento. 2a ed. Rio de Janeiro: Medsi; 2001.

2. Groves AM. Rheumatic fever and rheumatic heart disease: an overview. Trop Doct. 1999;29:129-32.

3. Besterman EM. Some notes on the history of rheumatic carditis. West Indian Med J. 2001;50:180-2.

4. Rocha $P$, Freitas $S$, Alvares $S$. Febre reumática - revisão casuística. Rev Port Cardiol. 2000;19:921-8.

5. Vardi P, Markiewicz W, Weiss Y, Levi J, Benderly A. Clinicalechocardiographic correlations in acute rheumatic fever. Pediatrics. 1983;71:830-4.

6. Talwar S, Rajesh MR, Subramanian A, Saxena A, Kumar AS. Mitral valve repair in children with rheumatic heart disease. ] Thorac Cardiovasc Surg. 2005;129:875-9.

7. Yuan SH, Doyle EF, Pisacano JC, Reed GE. Severe rheumatic mitral insufficiency in childhood amenable to surgery. Pediatrics. 1964;33:571-8.

8. D'Angelo WA, Fries JF, Masi AT, Shulman LE. Pathologic observations in systemic sclerosis (scleroderma). Am J Med. 1969;46:428-40.

9. Owens GR, Follansbee WP. Cardiopulmonary manifestations of systemic sclerosis. Chest. 1987;91:118-27.

10. Guttadauria M, Ellman H, Emmanuel G, Kaplan D, Diamond H. Pulmonary function in scleroderma. Arthritis Rheum. 1977;20:1071-9.

11. Celli BR. What is the value of preoperative pulmonary function testing? Med Clin North Am. 1993;77:309-25.

12. Wynne $R$, Botti M. Postoperative pulmonary dysfunction in adults after cardiac surgery with cardiopulmonary bypass: Clinical significance and implications for practice. Am J Crit Care. 2004;13:384-93.

13. Kantor Jr O. Testes de função pulmonar em crianças e adolescentes. J Pediatr. 1997;73:145-50.

14. Rodrigues JC, Cardieri JMA, Bussamra MHCF, Nakaie CMA, Almeida MB, Filho LVFS, et al. Provas de função pulmonar em crianças e adolescentes. J Pneumol. 2002;28(supl 3):S207-21.

15. Marostica PJ, Weist AD, Eigen H, Angelicchio C, Christoph K, Savage J, et al. Spirometry in 3- to 6-year-old children with cystic fibrosis. Am J Respir Crit Care Med. 2002;166:67-71.

16. Steen VD, Owens GR, Fino GJ, Rodnan GP, Medsger TA Jr. Pulmonary involvement in systemic sclerosis (scleroderma). Arthritis Rheum. 1985;28:759-67.

17. Tashkin DP, Clements PJ, Wright RS, Gong H Jr, Simmons MS, Lachenbruch PA, et al. Interrelationships between pulmonary and extrapulmonary involvement in systemic sclerosis. Chest. 1994;105:489-95.

18. Doenst T, Borger MA, David TE. Long-term results of bioprosthetic mitral valve replacement: the pericardial perspective. J Cardiovasc Surg. 2004;45:449-54.

19. Braun SR, Birnbaum ML, Chopra PS. Pre- and postoperative pulmonary function abnormalities in coronary artery revascularization surgery. Chest. 1978;73:316-20.

20. Ferdinande $P$, Lauwers $P$, Van Buyten $L$, Van de Walle J. Pulmonary function tests before and after open heart surgery. Acta Anaesthesiol Belg. 1980;31 Suppl:127-36.

21. Durand $M$, Combes $P$, Eisele $J H$, Contet A, Blin D, Girardet $P$. Pulmonary function tests predict outcome after cardiac surgery. Acta Anaesthesiol Belg. 1993;44:17-23.

22. Shenkman Z, Shir Y, Weiss YG, Bleiberg B, Gross D. The effects of cardiac surgery on early and late pulmonary functions. Acta Anaesthesiol Scand. 1997;41:1193-9. 
23. Ragnarsdóttir $M$, KristjAnsdóttir A, Ingvarsdóttir I, Hannesson P, Torfason B, Cahalin LP. Short-term changes in pulmonary function and respiratory movements after cardiac surgery via median sternotomy. Scand Cardiovasc J. 2004;38:46-52.

24. McGowan FX Jr, Ikegami M, del Nido PJ, Motoyama EK, Kurland G, Davis PJ, et al. Cardiopulmonary bypass significantly reduces surfactant activity in children. J Thorac Cardiovasc Surg. 1993;106:968-77.

25. Sulc J, Samanek M, Zapletal A, Voriskova M, Hucin B, Skovranek J. Lung function in VSD patients after corrective heart surgery. Pediatr Cardiol. 1996;17:1-6.

26. Sulc J, Andrle V, Hruda J, Hucin B, Samanek M, Zapletal A. Pulmonary function in children with atrial septal defect before and after heart surgery. Heart. 1998;80:484-8.
27. Candaele S, Herijgers P, Demeyere R, Flameng W, Evers G. Chest pain after partial upper versus complete sternotomy for aortic valve surgery. Acta Cardiol. 2003;58:17-21.

28. Macguire B, Royse C, Royse A, Duane M, Pang J. Lung function following cardiac surgery is not affected by postoperative ventilation time. Ann Thorac Cardiovasc Surg. 2000;6:13-8.

Correspondence:

Lívia B. de Andrade

Rua do Futuro, 17/1002, Aflitos

CEP 52050-010 - Recife, PE - Brazi

Tel.: +55 (81) 3231.4236, +55 (81) 9989.9712

E-mail: liviabandrade2005@yahoo.com.br,livia@fir.br 